\title{
The Risk Management Maturity Assessment: The Case of Indonesian Fintech Firm
}

\author{
Franciskus Antonius Alijoyo ${ }^{1}$, Ivonne Bonita ${ }^{2}$, and Kevin Bastian Sirait ${ }^{2, *}$ \\ ${ }^{1}$ Faculty of Economics, Parahyangan Catholic University, Indonesia \\ ${ }^{2}$ Center for Risk Management and Sustainability, Indonesia \\ *Corresponding author
}

\begin{abstract}
The purpose of this paper is to determine the risk management maturity level of an Indonesian financial technology (fintech) firm, uncovering the root cause of the firm's risk management maturity level, its barriers and challenges in implementing effective risk management, and provide recommendations for improvements. The Risk and Insurance Management Society Risk Maturity Model is applied to assess the firm's risk management maturity level. Furthermore, direct observation and interviews are also performed to analyze the firm's enterprise risk management practices. The risk management maturity level of the Indonesian fintech firm is at the lowest level (i.e., ad-hoc). The firm's past successful experiences lead to an apathetic attitude in embedding the risk management concepts within its practice, and this attitude affects the firm's judgment and decision-making capabilities in coping with its risks. Consequently, it significantly hinders the effectiveness and efficacy of the firm's risk management practice. This paper uncovers the risk management maturity level of an Indonesian fintech firm, in which the firms with similar circumstances can use the findings and recommendations from this paper to improve their risk management maturity.
\end{abstract}

Keywords: Risk and Insurance Management Society, Risk management maturity, Risk maturity model, Financial technology, Enterprise risk management

\section{Introduction}

The financial technology (fintech) industry has become a primary driver of changes and innovation nowadays, and its impact has already been felt throughout all financial services industries. Although the advancement of technology has become the primary driver in the emergence of the fintech industry and enables the banks to fulfill the demand of digital services for their customers, it increases the fintech firms and banks' risk exposures. The increases in risk exposure within the digital era come from the firms' external and internal environment. The increase of risk exposure that originated externally happens because of the increase in cybercrime (BCBS, 2018). On the other hand, the increase of risk exposure that originated internally is related to information technology (IT) governance, which includes the vulnerability within the banks and the fintech firms' systems (Alreemy et al., 2016). Due to this situation, the regulators have established some regulations to impose the technologicallydriven firms within the financial sector, especially the fintech firms, to implement structured 
and systematic enterprise risk management (ERM) to protect their customers, the public at large, and their internal organization against the risks.

In this regard, the Indonesian government has also imposed IT governance regulations on every technology-driven firm operated in Indonesia to ensure an adequate performance and safety level. Specifically, Bank Indonesia (BI), as the central bank of Indonesia, issued a directive under 19/12/PBI/2017 in 2017 concerning the financial technology implementation, which imposed all fintech firms that have already been registered in BI to implement the concept of cautionary and principles of risk management. Similar to the context of Arner et al. (2017), the IT governance regulations imposed on the firms are to improve financial stability, protecting their customers, maintain market integrity and development, and achieve the state of prudential safety and soundness.

The implementation of IT governance and the regulations introduced by the regulators are intended to protect every individual and institution from undesirable events (e.g., cybercrime, system error, or accident). An ineffective IT governance hinders the quality of the value creation process in utilizing IT to support its business activities. In some cases, the lack of IT governance can create a misalignment between the firm's strategic business objectives and the roles of its IT, weaken the firm's capability in integrating the mechanism of IT governance into the its business process, and also can create gaps in terms of the understanding and awareness of IT governance among the firm's senior management (Ko \& Fink, 2010).

Even though the regulations regarding the implementation of technology have their benefits to the firms, Packin (2018) explains that the regulations regarding the implementation of technology are not meant to be the ultimate remedy for the firms' existing corporate governance problems or challenges within the financial sector. Furthermore, the directives' implication varies from one fintech firm to another, depending on the respective organization's risk management maturity level. Thus, it might be a case where some fintech firms have an advanced level of risk management maturity, whereas the other ones have a shallow level of risk management maturity.

Against this background, the purpose of this research is to determine the risk management maturity level of an Indonesian fintech firm. Specifically, the research's objectives driving the assessment of an Indonesian fintech firm are presented as follows:

a. To shed light of the root cause of the fintech firm's current state ERM maturity level.

b. To uncover the barriers and challenges of the fintech firm in implementing effective ERM practice.

c. Provide recommendations for the fintech firm in improving its ERM maturity.

This research's findings can give the risk practitioners, the fintech firms, and any technology-driven organization more excellent knowledge and understanding on how to improve one's risk management maturity and utilize the appropriate ERM mechanism to create, protect, and enhance its value in coping with risks. 


\section{Research methodology}

This study's object is an Indonesian fintech firm registered in Bank Indonesia (BI) (i.e., Indonesia's central bank) as a payment services company. Furthermore, the fintech firm of interest uses the ISO 31000 standard as their point-of-reference in implementing ERM. As for the Indonesian fintech firm's name, it could not be disclosed due to the agreement to keep their name anonymous. However, to ease the explanation regarding the findings and the analysis, this study's object is referred to as firm X.

\subsection{Data collection and sample}

In assessing the risk management maturity and uncovering the root cause that hinders the ERM improvement of firm $X$, this study takes a qualitative approach through questionnaires and interviews. Direct observation of firm X ERM practice is also conducted to uncover the challenges and barriers that it has to deal with in implementing effective risk management. As for this study's participants, there are 19 participants, consisting of seven top management officers and twelve middle management officers. The list of participants and their position within the firm are presented in Table 1.

Table 1. Participants' position within the firm $X$

\begin{tabular}{|c|c|c|}
\hline \multicolumn{2}{|r|}{ Participants' functional position } & Department \\
\hline 1 & Chief executive officers (CEO) & - \\
\hline 2 & Chief operating officer (COO) & Operations \\
\hline 3 & Chief marketing officer (CMO) & Marketing \\
\hline 4 & Chief information officer (CIO) & IT \\
\hline 5 & Chief human resource officer (CHRO) & Human resource \\
\hline 6 & Chief financial officer (CFO) & Finance \\
\hline 7 & Chief risk officer (CRO) & Risk Management \\
\hline 8 & Manager of procurement, reconciliation, and settlement & Operations \\
\hline 9 & Manager of call center and branches & Operations \\
\hline 10 & Manager of product development & IT \\
\hline 11 & Manager of IT operational & IT \\
\hline 12 & Manager of finance and accounting & Finance \\
\hline 13 & Manager of treasury and operational finance & Finance \\
\hline 14 & Manager of marketing and sales & Marketing \\
\hline 15 & Manager of media & Marketing \\
\hline 16 & Manager of general affair & Human resource \\
\hline 17 & Manager of human resources & Human resource \\
\hline 18 & Manager of anti-money laundering and policy governance & Risk management \\
\hline 19 & Manager of legal and compliance & Risk management \\
\hline
\end{tabular}

Note: The total number of participants in this study are 19. In which, the participant number 1 to 7 are the top management officers of firm X. Whereas, the participant number 8 to 19 are the middle management officers of the firm $X$.

The questionnaire used in this study is based on the risk management maturity model developed by The Risk and Insurance Management Society (RIMS, 2006). It is composed of the value of 0 (lowest maturity) to 5 (highest maturity), which is applied in measuring the ERM maturity level of firm X under each attribute defined by RIMS (2006). Thus, the lowest risk management maturity level is non-existent; whereas, the highest risk management maturity level is leadership. This model is commonly known as the Risk and Insurance Management 
Society - Risk Maturity Model (RIMS RMM), and the descriptions of its components are elaborated further in the next subsection.

As for the information obtained from the interview with the participants, it is following the guidance provided by Yin (2016, pp. 184-245), which the processes of compiling, disassembling, reassembling, interpreting, and concluding the participants' responses are applied. All the interviews with the participants are recorded, transcribed, and then analyzed to find the similarities and discrepancies among the participants' responses. Furthermore, the series of questions used in the interview are based on the characteristics of the RIMS RMM attributes to obtain the reflection of the ERM practices of firm X.

Additionally, the interviews' findings are further enhanced with the direct observation of the firm's ERM practices to uncover the root cause that makes firm $X$ has the state of its ERM maturity in the first place and the barriers that prevent the firm from improving its risk management effectiveness and maturity. The firm has granted access and permission to the authors in analyzing the firm's documents (i.e., corporate governance mechanism, risk management mechanism, and the ISO 31000 standard used by the firm). Hence, it enabled us to understand and obtain insights into how firm X implements ERM within its business activities and uncovers the barriers and challenges in realizing effective risk management practice.

\subsection{RIMS risk maturity model (RIMS RMM)}

The RIMS RMM is defined as a statistically validated tool that can help the firm in identifying the gaps and provide a roadmap for the firm to improve its risk management capabilities, infrastructure, and governance (Minsky, 2008). Following the definition of RIMS RMM, the improvement of ERM maturity is not only considered as an objective but also as a tool or approach to improve the firm's capacity and capability in terms of identifying and managing the risks it encounters. According to Farrell and Gallagher (2015), the RIMS RMM is widely used all over the world, and it is used as a benchmarking tool for risk management maturity, and it also provides the firms with the mechanism for measuring their ERM maturity.

In terms of leveling, RIMS RMM provides five maturity levels, which are: (1) ad-hoc, (2) initial, (3) repeatable, (4) managed, and (5) leadership (Farrell \& Gallagher, 2015; Lindberg \& Seifert, 2011; Minsky, 2008). The maturity level of non-existent is added to represent the state in which the ERM mechanism does not exist or is limited within the firm, and the firm's perspective and recognition of the benefits of ERM is either insufficient or none. The interpretation of each level under RIMS RMM is described in Table 2.

Table 2. RIMS RMM maturity level and interpretation

\begin{tabular}{|l|l|}
\hline \multicolumn{1}{|c|}{ Level } & \multicolumn{1}{c|}{ Interpretation } \\
\hline 0. Non-existent & $\begin{array}{l}\text { The firm's recognition of ERM is limited. The firm's ERM implementation is either } \\
\text { insufficient or none, and there is no risk management framework within the firm, which } \\
\text { includes risk indicators, risk measurement, and objectives. }\end{array}$ \\
\hline 1. Ad-hoc & $\begin{array}{l}\text { The level of risk management within the firm is in a primitive stage. The } \\
\text { implementation of risk management is depended on the actions of certain individuals } \\
\text { by using improvised procedures and minimum knowledge of the process. }\end{array}$ \\
\hline
\end{tabular}




\begin{tabular}{|l|l|}
\hline \multicolumn{1}{|c|}{ Level } & \multicolumn{1}{c|}{ Interpretation } \\
\hline 2. Initial & $\begin{array}{l}\text { The risks are managed in silos, and there is a little aggregation of risk or risk integration. } \\
\text { In which, the processes are accompanied by the lack of discipline. The definition of the } \\
\text { risk may vary. }\end{array}$ \\
\hline 3. Repeatable & $\begin{array}{l}\text { The framework of risk assessment is in place, and the board of directors conducts the } \\
\text { risk overview. The implementation of risk management is established and conducted } \\
\text { repeatably. }\end{array}$ \\
\hline 4. Managed & $\begin{array}{l}\text { The implementation of ERM is established in the firm, and each aspect of ERM is } \\
\text { integrated and harmonized, along with its measurement and controls. The ERM } \\
\text { procedures and its principles are communicated and understood by the firm. }\end{array}$ \\
\hline 5. Leadership & $\begin{array}{l}\text { Within the strategic level of the firm, the risk-based discussion is already taken place. } \\
\text { Moreover, risk tolerance and appetite are understood within executive management and } \\
\text { board of directors and accompanied by the alerts to inform the top management if the } \\
\text { risk threshold is exceeded. }\end{array}$ \\
\hline
\end{tabular}

Notes: the interpretation of each level is adapted from Farrell and Gallagher (2015), Lindberg and Seifert (2011), Minsky (2008), and RIMS (2006).

As for the attributes and competency drivers of the RIMS RMM, it consists of seven attributes, 25 competency drivers, and 68 readiness indicators in measuring the firm's risk management maturity level (Minsky, 2008). Each of these attributes, along with its components, measures the systematic effects of the firm's risk management practices and the influence it brings to the firm's risk management capabilities in managing the risks in an aggregated manner. The attributes within RIMS RMM, its competency drives, and the purpose for each of these attributes are presented in Table 3.

Table 3. RIMS RMM attributes, its competency drivers, and purpose

\begin{tabular}{|c|c|c|}
\hline Attributes & Competency drivers & Purpose \\
\hline $\begin{array}{l}\text { A. Adoption of } \\
\text { ERM-based } \\
\text { approach }\end{array}$ & $\begin{array}{l}\text { A.1. Executive support for ERM } \\
\text { A.2. Business process definition and risk } \\
\text { ownership } \\
\text { A.3. Front line and support process owner } \\
\text { participation } \\
\text { A.4. Far-sighted risk management vision }\end{array}$ & $\begin{array}{l}\text { Determine the extent and the } \\
\text { intensity of the support for ERM. }\end{array}$ \\
\hline $\begin{array}{l}\text { B. ERM process } \\
\text { management }\end{array}$ & $\begin{array}{l}\text { B.1. ERM process oversight } \\
\text { B.2. Risk culture, accountability, and } \\
\text { communication } \\
\text { B.3. ERM process steps } \\
\text { B.4. Repeatability and scalability } \\
\text { B.5. Risk management reporting }\end{array}$ & $\begin{array}{l}\text { Focuses on measuring the level of } \\
\text { integration of the ERM into the } \\
\text { firm's daily activities or practices. } \\
\text { Particularly, the extent of risk } \\
\text { management integration within the } \\
\text { firm's business units. }\end{array}$ \\
\hline $\begin{array}{l}\text { C. Risk appetite } \\
\text { management }\end{array}$ & $\begin{array}{l}\text { C.1. Risk portfolio view } \\
\text { C.2. Risk-reward tradeoffs }\end{array}$ & $\begin{array}{l}\text { Determine the firm's level of } \\
\text { understanding about risk, its } \\
\text { consequences, and tradeoffs along } \\
\text { with its risk tolerance. }\end{array}$ \\
\hline $\begin{array}{l}\text { D. Root cause } \\
\text { discipline }\end{array}$ & $\begin{array}{l}\text { D.1. Risk and opportunity information collection } \\
\text { D.2. Root cause consideration } \\
\text { D.3. Dependencies and consequences } \\
\text { D.4. Information classifications }\end{array}$ & $\begin{array}{l}\text { Focuses on the firm's capability in } \\
\text { identifying the risks to minimize its } \\
\text { impact and maximize the value of } \\
\text { the opportunities. }\end{array}$ \\
\hline $\begin{array}{l}\text { E. Uncovering } \\
\text { risks }\end{array}$ & $\begin{array}{l}\text { E.1. Adverse events as opportunities } \\
\text { E.2. Follow-up reporting } \\
\text { E.3. Formalized risk indicators and measures } \\
\text { E.4. Risk ownership by business areas }\end{array}$ & $\begin{array}{l}\text { Determine the firm's capability to } \\
\text { measure and report on-going risk } \\
\text { and its risk identification abilities } \\
\text { and mitigation. }\end{array}$ \\
\hline
\end{tabular}




\begin{tabular}{|l|l|l|}
\hline \multicolumn{1}{|c|}{ Attributes } & \multicolumn{1}{|c|}{ Competency drivers } & \multicolumn{1}{c|}{ Purpose } \\
\hline $\begin{array}{l}\text { F. Performance } \\
\text { management }\end{array}$ & $\begin{array}{l}\text { F.1. Communicating goals } \\
\text { F.2. ERM information and planning } \\
\text { F.3. ERM process goals and activities }\end{array}$ & $\begin{array}{l}\text { Focuses on the firm's capability to } \\
\text { execute its strategies and its vision } \\
\text { with its risk management approach. }\end{array}$ \\
\hline $\begin{array}{l}\text { G. Business } \\
\text { resiliency and } \\
\text { sustainability }\end{array}$ & $\begin{array}{l}\text { G.1. Resiliency and operational planning } \\
\text { G.2. Understanding consequences } \\
\text { G.3. Risk-based planning }\end{array}$ & $\begin{array}{l}\text { The firm's ability to recover from a } \\
\text { setback, protect, and maintain its } \\
\text { value from the risks and the extent } \\
\text { of the firm in integrating the } \\
\text { activities in value protection and } \\
\text { recovery. }\end{array}$ \\
\hline
\end{tabular}

Note: the detailed explanations of the attributes of ERM RMM can be seen in Farrell and Gallagher (2015) and Minsky (2008). For the detailed assessment of RIMS RMM, it can be accessed at https://www.rims.org/resources/strategic-enterprise-risk-center/risk-maturity-model.

Since there are 68 readiness indicators within RIMS RMM, the questionnaire's total number of questions are follows suit. The Likert scale of 0 to 5 is applied for each of the questions within the questionnaire answered by the participants. Accordingly, for each of the readiness indicators, competency drivers, and attributes, it uses the 0 to 5 maturity scale to determine the firm X risk management maturity for all the aspects defined by RIMS (2006). The value of 0 indicates the lowest maturity score, whereas the value of 5 indicates the highest maturity score. Hence, in determining firm X maturity in risk management, it follows the steps below.

a. First, each competency drivers' maturity score is obtained by calculating the average score for all readiness indicators that belong to the specific competency drivers. It is determined by applying the formula $C D_{i}=\frac{1}{N} \sum_{x=1}^{n} \overline{I_{x, i}}$. In which $C D_{i}$ represents the maturity score of competency driver $i, \overline{I_{x, i}}$ represents the average of the participants' score of readiness indicator $x$ that is associated with competency driver $i$, and $N$ represents the total number of readiness indicators that belong to the specific competency driver.

b. Second, the maturity score of the firm's risk management maturity, it is obtained by averaging each competency drivers' score. It is obtained by applying the $M=$ $\frac{1}{N} \sum_{i=1}^{n} C D_{i}$. Where $M$ represents the firm's maturity score, $C D_{i}$ represents the maturity score of competency driver $i$, and $N$ represents the number of competency drivers within the RIMS RMM.

c. Lastly, the maturity score is then matched with the risk management maturity intervals as suggested by RIMS RMM. The intervals are given as follows: (1) Non-existent: $M<$ 1, (2) ad-hoc: $1 \leq M<2$, (3) initial: $2 \leq M<3$, (4) repeatable: $3 \leq M<4$, (5) managed: $4 \leq M<5$, and (6) leadership: $M=5$. In which, $M$ represents the firm's risk management maturity score.

\section{Findings and discussion}

\subsection{Fintech firm $\mathbf{X}$ maturity score}

Based on the assessment, the overall risk management maturity score of firm X is 1.765 or at the level of ad-hoc in accordance with the RIMS RMM. The result implies that the implementation of risk management of firm $\mathrm{X}$ is dependent on the actions of particular 
individuals with the minimum knowledge of risk management. The detailed risk management maturity score of firm X under the definition construed by RIMS RMM is presented in Table 4.

Table 4. Firm X maturity score

\begin{tabular}{|c|c|c|c|}
\hline+2 & Competency drivers & Scores & Maturity level \\
\hline \multirow{4}{*}{ A. Adoption of ERM-based approach } & A.1 & 1.996 & Ad-hoc \\
\hline & A. 2 & 3.134 & Repeatable \\
\hline & A. 3 & 1.723 & Ad-hoc \\
\hline & A. 4 & 1.208 & Ad-hoc \\
\hline \multicolumn{2}{|l|}{ Average } & 2.015 & Initial \\
\hline \multirow{5}{*}{ B. ERM process management } & B.1 & 2.732 & Initial \\
\hline & B. 2 & 2.125 & Initial \\
\hline & B. 3 & 0.863 & Non-existent \\
\hline & B. 4 & 1.137 & Initial \\
\hline & B.5 & 0.827 & Non-existent \\
\hline \multicolumn{2}{|l|}{ Average } & 1.537 & Ad-hoc \\
\hline \multirow[t]{2}{*}{ C. Risk appetite management } & C.1 & 0.653 & Non-existent \\
\hline & C. 2 & 1.710 & Ad-hoc \\
\hline \multicolumn{2}{|l|}{ Average } & 1.182 & Ad-hoc \\
\hline \multirow[t]{4}{*}{ D. Root cause discipline } & D.1 & 1.161 & Ad-hoc \\
\hline & D. 2 & 1.661 & Ad-hoc \\
\hline & D.3 & 2.004 & Initial \\
\hline & D. 4 & 1.760 & Ad-hoc \\
\hline \multicolumn{2}{|l|}{ Average } & 1.647 & Ad-hoc \\
\hline \multirow{4}{*}{ E. Uncovering risks } & E.1 & 1.738 & Ad-hoc \\
\hline & E. 2 & 1.155 & Ad-hoc \\
\hline & E. 3 & 1.321 & Ad-hoc \\
\hline & E. 4 & 3.304 & Repeatable \\
\hline \multicolumn{2}{|l|}{ Average } & 1.880 & Ad-hoc \\
\hline \multirow[t]{3}{*}{ F. Performance management } & F.1 & 3.112 & Repeatable \\
\hline & F.2 & 1.202 & Ad-hoc \\
\hline & F.3 & 1.904 & Ad-hoc \\
\hline \multicolumn{2}{|l|}{ Average } & 2.073 & Initial \\
\hline \multirow[t]{3}{*}{ G. Business resiliency and sustainability } & G.1 & 2.183 & Initial \\
\hline & G.2 & 3.271 & Repeatable \\
\hline & G.3 & 0.622 & Ad-hoc \\
\hline \multicolumn{2}{|l|}{ Average } & 2.025 & Initial \\
\hline \multicolumn{2}{|l|}{ Firm $X$ maturity score and level } & 1.765 & Ad-hoc \\
\hline
\end{tabular}

Note: the attributes' competency drivers of RIMS RMM are presented in Table 3.

Following the risk management mature assessment presented in Table 4, firm X executives already acknowledge the necessity of ERM, and the firm has established the risk management department to prove their commitment. Nevertheless, ERM's mechanism only applies to two departments, namely the risk management department and the IT department. The role and function of the risk management department tend to focus on dealing with legal risk. On the other hand, the IT department manages operational risk and cyber risk. Hence, there is no integration between the two departments' ERM mechanism in providing each other with the risk-related information, and the ERM process of the two departments is not consistently conducted. 
Firm $\mathrm{X}$ has the attitude of being reactive towards the problems that have occurred instead of proactive in preventing the problems. These findings are further enhanced by the informal procedure used by firm $X$ to distribute the risk-related information to all the firm's internal stakeholders. Such informal procedures have made all the firm's departments not strictly applying the risk reporting and risk communication procedure, as suggested by the ISO 31000 standard. As for the lack of risk assessment, it is discovered that not all the employees and the executives of firm $\mathrm{X}$ is familiar or have the capability in using the risk management tools in assessing risks, which hinders their effectiveness in producing an accurate and precise risk assessment results that can be used to enhance the firm's value and its business performance.

Among all the attributes of RIMS RMM, the attribute of performance management of firm $\mathrm{X}$ has the highest maturity score. The firm $\mathrm{X}$ competency driver of communicating goals reaches the level of repeatable due to all executives and managers within the middle management have understood and acknowledged the role of ERM and the benefits it could bring to the firm. However, the ERM level of understanding and acknowledgment of firm $\mathrm{X}$ is not matched with an adequate ERM implementation level to achieve effective integrated ERM within its business activities. At this stage, each of the departments has formulated their own plan to achieve their respective objectives, and each of the departments' plans toward the implementation of ERM is not applied holistically due to the lack of experts in risk management within the firm.

In terms of business resiliency and sustainability, firm $\mathrm{X}$ has a disaster recovery center (DRC) to deal with potential problems regarding their servers. And yet, the concept of DRC from the firm standpoint is limited compared to the much larger concept about business resiliency and sustainability. For instance, the current usage of the firm's DRC is designed and operated to address the elementary issues of the cases of downed servers due to the power outage and dealing with some basic cyber attacks (e.g., phishing and denial-of-service).

Although firm X uses the ISO 31000 standard as its guideline in implementing and developing its ERM, the firm's scope in viewing the risks they encountered is limited. The role and function of the firm's risk management department focus on its own tasks instead of consolidating and aligning all the firm's departments ERM plan, their risk approach, and their perception of risks in achieving a holistic risk management process. Thus, due to the lack of support and guidance from the risk management department, the ERM mechanism of firm X is not structured to operate holistically, and the quality and the effectiveness of the firm's ERM are solely dependent on the experience and intuition of its employee instead of following the guideline recommended by the ISO 31000 standard in conducting the risk management process within the firm.

\subsection{The root cause of the firm's maturity score and its impact}

Based on the findings from the observations at firm $X$ and the interviews with the firm's executives and managers, the underlying cause of the firm's low risk management maturity is due to the apathetic attitude and perspective toward the implementation of ERM. Hence, this apathetic attitude harms the firm's quality and performance in establishing and developing an effective risk management process. 
Due to the establishment of the risk management department and the ERM implementation are to conform with the regulations instead of the necessity in using the ERM to enhance the firm's value, the executives of the firm $X$ do not show any interest in implementing and developing the ERM to its full potential. This is because the firm's executives have experienced a series of successes since its establishment until early 2019. The decisions and actions that have been made are merely expanding business matters, and none of its associated risks has been considered. The most common terms that the firm used for risk management are related to the basic technicalities of IT issues, its hardware, and its fintech applications. And yet, they say it is ERM.

As explained by Power (2009), the implementation of ERM within the firm for the compliance purpose demands the firm to extensively ensure the firm operates in accordance with the specified regulations on a daily basis, which enables the firm to focus and maintain its internal performance through the rule-based procedure and definite system. However, in the case of firm $X$, the firm's scope and attitude towards risks (e.g., risk appetite, risk tolerance, and risk capacity) do not exist within its internal control mechanism and procedural details, and the concept of ERM is not embedded within the firm's business activities and the decisionmaking of its executives and managers. In general, the root cause of the low level in risk management maturity of firm $X$ is similar to the findings of Zhao et al. (2014). However, within the context of firm X, the effectiveness and the quality of the firm's ERM process are severely hindered due to the intention and purpose for the risk management implementation is only to conform with the regulations sets by BI.

\subsection{The barriers and challenges of implementing effective ERM}

According to the result of firm $\mathrm{X}$ risk management maturity and the findings from the participants' information regarding the ERM state within the firm, the primary barrier in the risk management implementation within the firm is highly concentrated with the firm's attitude and perception in understanding and embracing the concept of ERM which affects the quality of the ERM integration into the firm's activities and decision-making. The firm's priority in implementing the risk management mechanism is to conform with the Indonesian fintech regulation rather than creating and protecting its value through ERM. Consequently, the apathetic attitude of firm $\mathrm{X}$ towards the risk management implementation has posed sets of challenges in achieving a holistic and integrated ERM process within the firm. Namely, (1) the implementation of ERM within the firm is solely based on the employees' experience and intuition in integrating the risk management mechanism into the department's activities, (2) there is a lack of integration and co-operation among the firm's department in conducting the ERM process, (3) the lack of risk management experts within the firm to aid the firm in aligning the departments' perception and standard operating procedure from the risk management standpoint, (4) the lack of knowledge and familiarity in using the ERM tools, (5) inadequacy in conducting risk reporting and documentation within most of the departments, and (6) the firm has imperfect information regarding the nature of the risk (e.g., the scale, the impact, and the triggers of the risk) due to the subpar flow of risk-oriented information among all the firm's management. 


\subsection{Recommendation on improving the firm's ERM maturity}

Based on the risk management maturity assessment of firm $\mathrm{X}$ and the root cause analysis of its risk management maturity, several recommendations are suggested to help the firm improve its risk management maturity level and enable them to create and protect its value more effectively through ERM utilization.

The first recommendation is to build a strong foundation for risk management awareness and ownership, which consists of: (1) building awareness and right understanding about risk management at the board level and senior management through series of executive briefings, (2) building commitment of the board to take risk leadership and ownership to adopt a systematic risk management approach which emphasizes on the principles, framework, and process of risk management at all levels of the organization, and (3) building awareness about risk management to all employee through series of training, focus group discussion, and the certification on personnel risk management competency, and at the later stage, in building the risk ownership at all level of the firm's management, it is recommended to linking their work performance indicator with risk management.

The second recommendation is to rearrange the firm's priority and purpose in using risk management. Since the firm has adopted the ISO 31000 standard as their guideline in implementing ERM, it is recommended to (1) establishing risk management policy and standard operating procedure from the level of strategic decision-making process down to the level of operational business process, (2) linking the risk management elements to the employees' key performance indicators, and (3) implementing consistently and thoroughly the three pillars of ISO 31000 standard, namely the principles, framework, and process of risk management.

Lastly, the third recommendation is to integrate the implementation of ISO 31000 standard into all aspect of the firm $X$, which at least: (1) synchronizing the firm's ERM program with its objectives, so all employee would be able to see the importance and relevancy of risk management to the firm's sustainability, (2) embedding the risk management process explicitly into the firm's strategies in achieving its objectives in order for the employees to understand the criticality and importance and of risk management in the firm's strategies and build strong risk ownership, (3) ensuring the availability of resources in implementing risk management to the firm, (4) regularly conduct evaluations of the firm's performance based on the identified risks and its impact, (5) communicating the firm's policies regularly and its standing and focus on managing and coping with the identified risks, and (6) regularly evaluating the progress of the risk management implementation within the firm.

\section{Conclusion}

This study assesses the ERM maturity level of an Indonesian fintech firm (i.e., firm X), uncover the root cause by which it is making the firm $\mathrm{X}$ has its current risk management maturity level, along with the barriers and challenges that hinder its capabilities in applying an effective risk management practice. Additionally, it is to provide recommendations that can be used by firm $X$ in improving its ERM maturity. 
The ERM maturity assessment results suggest that the overall ERM maturity of firm X is at the level of ad-hoc. It is implied that firm $\mathrm{X}$ is at a state of incapability and out-of-capacity to embrace the ERM approach to protect and create the firm's value. Particularly on the regulatory compliance aspect, all the regulations and requirements imposed by the regulator (i.e., Indonesia's central bank) regarding the mandatory implementation of ERM have been fulfilled by the firm. However, performance-wise, the firm's ERM process's quality and effectiveness are subpar. Although firm X has adopted the ISO 31000 standard as its guideline in implementing and integrating ERM process within its activities, the role of its risk management department is solely to cope with legal risk, whereas its IT department manages the general risks of the firm. Consequently, the firm's limited scope and perception of the necessity in applying risk management hindered the quality and the effectiveness of its ERM process in identifying and managing the risks holistically.

The root cause of firm X's low ERM maturity level is its apathetic attitude towards the concept and the role of risk management within the firm. Due to the implementation of ERM is driven by the regulator's requirements and regulations, the definition and explanation of risks and ERM are not explicitly articulated and presented within the firm's internal control mechanisms and procedural details. Thus, the firm's flow of risk-related information is limited because it is only circulated only to two departments (i.e., risk and IT departments).

Since this study is based on a case study approach, some limitations should be noted. Specific conditions of firm X under this study would not be the same as the other fintech firms either in Indonesia or any other parts of the world. The results and recommendations are practically valid for the particularly concerned fintech firm in this study. Accordingly, it is recommended to conduct further research that considers multiple fintech firms to uncover the average level of ERM maturity of an Indonesian fintech industry and shed light on the underlying barriers and challenges that hinder the fintech firms from upgrading their ERM maturity. By which, it intends to increase the generability of future research findings in assessing the ERM maturity level of fintech firms and their industry. Additionally, for every fintech firm that uses the ISO 31000 standard as its guideline, it is recommended to consider applying the ERM maturity model that is explicitly designed under the requirements and specifications of the ISO 31000 standard in assessing and improving its ERM effectiveness and maturity level.

\section{References}

Alreemy, Z., Chang, V., Walters, R., \& Wills, G. (2016). Critical success factors (CSFs) for information technology governance (ITG). International Journal of Information Management, 36(6, Part A), 907-916. https://doi.org/10.1016/j.ijinfomgt.2016.05.017

Arner, D. W., Barberis, J., \& Buckley, R. P. (2017). FinTech, RegTech, and the Reconceptualization of Financial Regulation. Northwestern Journal of International Law \& Business, 37(3), 371-413.

BCBS. (2018). Sound Practices: Implications of fintech developments for banks and bank supervisors. Bank for International Settlements.

Farrell, M., \& Gallagher, R. (2015). The Valuation Implications of Enterprise Risk 


\section{IIMIICONF}

4th International Conference On Research In MANAGEMENT AND ECONOMICS

7-9 May 2021

Milan, Italy

Management Maturity. Journal of Risk and Insurance, 82(3), 625-657. https://doi.org/10.1111/jori.12035

Ko, D., \& Fink, D. (2010). Information technology governance: an evaluation of the theorypractice gap. Corporate Governance: The International Journal of Business in Society, 10(5), 662-674. https://doi.org/10.1108/14720701011085616

Lindberg, D. L., \& Seifert, D. L. (2011). Enterprise Risk Management (ERM) Can Assist Insurers in Complying with the Dodd-Frank Act. Journal of Insurance Regulation, 30(13), 319-337.

Minsky, S. (2008). RIMS State of ERM Report 2008. The Risk and Insurance Management Society, Inc. (RIMS).

Packin, N. G. (2018). RegTech, compliance and technology judgment rule. Chicago-Kent Law Review, 93(1), 193-218.

Power, M. (2009). The risk management of nothing. Accounting, Organizations and Society, 34(6), 849-855. https://doi.org/10.1016/j.aos.2009.06.001

RIMS. (2006). RIMS Risk Maturity Model (RMM) for Enterprise Risk Management. The Risk and Insurance Management Society, Inc.

Yin, R. K. (2016). Qualitative Research: From Start to Finish (2nd ed.). The Guilford Press.

Zhao, X., Hwang, B.-G., \& Low, S. P. (2014). Investigating Enterprise Risk Management Maturity in Construction Firms. Journal of Construction Engineering and Management, 140(8), 05014006. https://doi.org/10.1061/(ASCE)CO.1943-7862.0000873 